\title{
Experimental Determination of Dispersion Coefficient in Soil
}

\author{
Anthony .C. Ekeleme ${ }^{a^{*}}$, Jonah .C. Agunwamba ${ }^{\text {a }}$ \\ ${ }^{a}$ Department of Civil Engineering University of Nigeria, Nsukka, Enugu State, Nigeria
}

\begin{abstract}
Unsaturated soil dispersion experiment was done using three different soil samples which includes sand, clay and silt soil. The objective of the study is to determine experimentally dispersion coefficient in soil. Each sample was gradually introduced into a fabricated iron column, having a length of horizontal column $30 \mathrm{~cm}$ and vertical part $60.96 \mathrm{~cm}$. A solution of silver nitrate was allowed to pass through the vertical column down to the horizontal part. Samples of soil were collected at a constant distance of $10 \mathrm{~cm}$ and time interval of $5 \mathrm{mins}$ for $60 \mathrm{mins}$. The concentration of nitrate was taken at a constant distance of $10 \mathrm{~cm}$. This was done three times for each of the soil sample. Thereafter, the dispersion coefficient was calculated, and a regression dispersion model developed as a function of permeability, average diameter of sieve, velocity of flow and time taken to flow. The model was calibrated and verified with experimental results and found to have a high correlation coefficient (r) of 0.943. Data obtained from the experiments were fitted into the two existing models and poor correlation coefficients of -0.529 and -0.524 were obtained respectively.
\end{abstract}

\section{Keywords:}

Dispersion;

Silver Nitrate;

Column Experiment;

Model;

Soil Sample.

\section{Article History:}

Received: 03 June 2018

Accepted: 26 August 2018

\section{1- Introduction}

The behavior of solutes and cations under various climate and soil conditions can be assessed using models that simulate solute transport [1]. Solute transport in soil is affected by a large number of physical, chemical, and microbial soil properties. The solute transport in the porous media is a key factor in soil physics for understanding root zone leaching rate and addressing chemical pollution, loss of nutrients, groundwater contaminating rate, the salt distribution profiles and drainage water quality [2]. Concern about soil and water pollution has led to several studies focused on water and solute transport processes in soil. However, most studies of flow through porous media are conducted on a macroscopic scale where Darcy's law is valid. Hydrodynamic dispersion refers to the spreading of a solute at the macroscopic (Darcy) level by the combined action of mechanical dispersion and molecular diffusion [3, 4]. Mechanical dispersion is caused by the changes in the magnitude and direction of velocity across any pore cross-section at the microscopic level. Pores differ in size and shape, also causing variation in the maximum velocity within individual pores, in addition to velocity fluctuations in space with respect to the mean direction of flow. This results in a complex distribution of the flow velocity. Molecular diffusion results from variation of solute concentration within the liquid phase and causes the solute to move from regions of higher concentration to regions of lower concentration. Dispersion is caused by a number of factors such as diffusion, pore size, path length and friction in pores, fluid will move faster through the centre of a pore than along the edges. Dispersion results in a decrease in contaminant concentration through mixing or dilution both along the flow path (longitudinal dispersion) and normal to the flow path (transverse dispersion). Numerous studies on dispersivity length showed that it increases with travel distance of solute. Therefore, the main objective of the study is to determine regression dispersion model in soil by performing a column tests using silver nitrate as a tracer.

\footnotetext{
* CONTACT: Chytony4real09@yahoo.com

DOI: http://dx.doi.org/10.28991/esj-2018-01145

(C) This is an open access article under the CC-BY license (https://creativecommons.org/licenses/by/4.0/).
} 


\section{2- Materials and Methods}

\section{2-1- Dispersion in Soil}

A model framework was developed to model the dispersion of contaminants in sandy, clay and silt soil. The framework utilizes the vertical column attached with a horizontal column to account for on ground nitrogen sources and corresponding loadings. The vertical column has $0.275 \mathrm{~cm}$ internal diameter, vertical column length of $60.96 \mathrm{~cm}$, with $5 \mathrm{~cm}$ internal diameter of horizontal cross section area and a horizontal length of $30 \mathrm{~cm}$.

Moreover, $500 \mathrm{~g}$ of $2 \mathrm{~mm}$ sieved air dried soil of pre-determined textural class (sandy, silt and clay soils) were weighed out using a top loading mettler weighing balance. The sample was gradually introduced into the iron column. $1000 \mathrm{ml}$ of $100 \mathrm{mg} / \mathrm{l} \mathrm{AgNO}_{3}$ was poured through the column and allowed to drain through the soil. Sample of the saturated soil was collected at 1, 5, 10, 15, 20, 25, 30, 35, 40, 45, 50, 55 and 60 minutes interval at a constant distance of $10 \mathrm{~cm}$. One $(1 \mathrm{~g})$ of the sample was introduced into the extraction tube and $50 \mathrm{ml}$ of $2.5 \mathrm{~N} \mathrm{KCl}$ added and shook for about 2 hours. The sample was filtered through a No 42 What man filter paper into a 50 ml volumetric flask and made up to the mark with the extraction reagent.

A "Markham" distillation apparatus was set up and $10 \mathrm{ml}$ of the extract introduced into the apparatus, $10 \mathrm{ml}$ of $45 \%$ $\mathrm{NaOH}$ was gradually added to the sample and allowed to distill into a $10 \mathrm{ml}$ of $4 \% \mathrm{H}_{3} \mathrm{BO}_{3}$, the distillate is then titrated with $0.02 \mathrm{~N} \mathrm{H}_{2} \mathrm{SO}_{4}$ and the produced recorded as $\mathrm{NH}_{4}-\mathrm{N}$, a pinch of Devader alloy was added to the residual sample and the reaction oxidizes the nitrogen form to $\mathrm{NO}_{3}{ }^{-} \mathrm{N}$ about $50 \mathrm{ml}$ distillate was also collected into another $10 \mathrm{ml}$ of $4 \%$ $\mathrm{H}_{3} \mathrm{BO}_{3}$ and titrated with the same $0.02 \mathrm{~N} \mathrm{H}_{2} \mathrm{SO}_{4}$ and the produced recorded as $\mathrm{NO}_{3}{ }^{-} \mathrm{N}$. Hence, the dispersion in soil were determined using the below equation [5].

$D=\frac{M^{2} \pi}{4 \theta^{2} C^{2} t}$

Where $M=$ is the amount of silver nitrate $\left(\mathrm{AgNO}_{3}\right)$

That diffused into the soil $\left(\mathrm{g} / \mathrm{cm}^{2}\right)$

$$
\begin{aligned}
& C=\text { The concentration at a distance after dispersion over time }\left(\mathrm{g} / \mathrm{cm}^{3}\right), \\
& \theta=\text { Moisture content of the soil, } \\
& \pi=3.142 \\
& \mathrm{t}=\text { Corressponding time interval (secs) }
\end{aligned}
$$

\section{2-2- Statistical Regression Model of Dispersion in Soil}

Statistical analyses were used to develop a regression model for dispersion coefficient. A regression dispersion model developed as a function of permeability, average diameter of sieve, velocity of flow and time taken to flow. Where D is the dispersion coefficient. In other to make $\mathrm{D}$ a function;

$$
\text { Let } \quad D=f(d, k, t, v)
$$

Where $\mathrm{D}$ is the dispersion coefficient.

$$
\begin{aligned}
& \mathrm{d}=\text { Average diameter of sieves }(\mathrm{cm}), \\
& \mathrm{k}=\text { Permeability }(\mathrm{cm} / \mathrm{s}), \\
& \mathrm{t}=\text { Time of flow },(\mathrm{s}) \\
& \mathrm{v}=\text { Velocity of flow in }(\mathrm{cm} / \mathrm{s})
\end{aligned}
$$

Such that

$$
D=\alpha_{0} t^{\alpha_{1}} \times V^{\alpha_{2}} \times K^{\alpha_{3}} \times d^{\alpha_{4}}
$$

Taking the natural logarithm for both sides [6.7].

$$
\ln D=\propto_{0}+\propto_{1} \ln t+\propto_{2} \ln v+\propto_{3} \ln k+\propto_{4} \ln d
$$

Replacing $\ln D, \ln t, \ln v, \ln k$ and $\operatorname{lnd}$ by $y, x_{1}, x_{2}, x_{3}$ and $x_{4}$ respectively gives; 
$y=\propto_{0}+\propto_{1} x_{1}+\propto_{2} x_{2}+\propto_{3} x_{3}+\propto_{4} x_{4}$

Thus, $y=\propto_{0}+\sum_{i=1}^{n=4} \propto_{i} x_{i}$

In other to obtain $\propto_{i,}(i=0$ to 4$)$

Using least square method;

$$
\left(\begin{array}{llllll}
\sum y & n & \sum x_{1} & \sum x_{2} & \sum x_{3} & \sum x_{4} \\
\sum x_{1} \mathrm{y} & \sum x_{1} & \sum x_{1}{ }^{2} & \sum x_{1} x_{2} & \sum x_{1} x_{3} & \sum x_{1} x_{4} \\
\sum x_{2} \mathrm{y} & \sum x_{2} & \sum x_{1} x_{2} & \sum x_{2}{ }^{2} & \sum x_{2} x_{3} & \sum x_{2} x_{4} \\
\sum x_{3} \mathrm{y} & \sum x_{3} & \sum x_{1} x_{3} & \sum x_{2} x_{3} & \sum x_{3}{ }^{2} & \sum x_{3} x_{4} \\
\sum x_{4} \mathrm{y} & \sum x_{4} & \sum x_{1} x_{4} & \sum x_{2} x_{4} & \sum x_{3} x_{4} & \sum x_{4}{ }^{2}
\end{array}\right)=\left(\begin{array}{c}
\propto_{0} \\
\propto_{1} \\
\propto_{2} \\
\propto_{3} \\
\alpha_{4}
\end{array}\right)
$$

The above equations were used to determine the constants of $\propto_{0}, \propto_{1}, \propto_{2}, \propto_{3}$ and $\propto_{4}$ after tabulation.

\section{2-3- Model Calibration}

The model calibration were necessary in other to determine the values of the parameters that can fit the model to the system [6]. In essence of this, the calibration was deduced from the experimental data. In calibration, half of the experimental data is used and half used for verification.

\section{2-4- Verification}

Model evaluation involves determining how well the mathematical model describes the system [6]. This was achieved by conducting a set of measurements from the system used in creating the model. The remaining data were used for verification.

\section{2-5- Results and Discussion}

The experimental results of sand, clay and silt soil generated from experiments were used to calculate dispersion using Equation 1. Thereafter, the dispersion coefficient was calibrated and verified. The reason for this is to ascertain if the developed model really satisfies the system being modeled. The Figure 1 and 2, below shows the calibration and the verification of the model.

\section{2-6- Model Development}

In the development of the regression model, the variables in Equation 2 were fixed as defined in Equation 3 to 11, and thereafter regressed, thus;

$$
D=\frac{e^{6.353} \times K^{0.411}}{t^{2.139} \times V^{1.143} \times d^{0.034}}
$$

\section{2-7- Calibration of Dispersion Model}

The regression model given in Equation 12 was used to calibrate dispersion coefficient and thereafter verified using the measured dispersion. From the result, both has good agreement with $\mathrm{R}^{2}$ value of 0.991 as shown in Figure 2. 


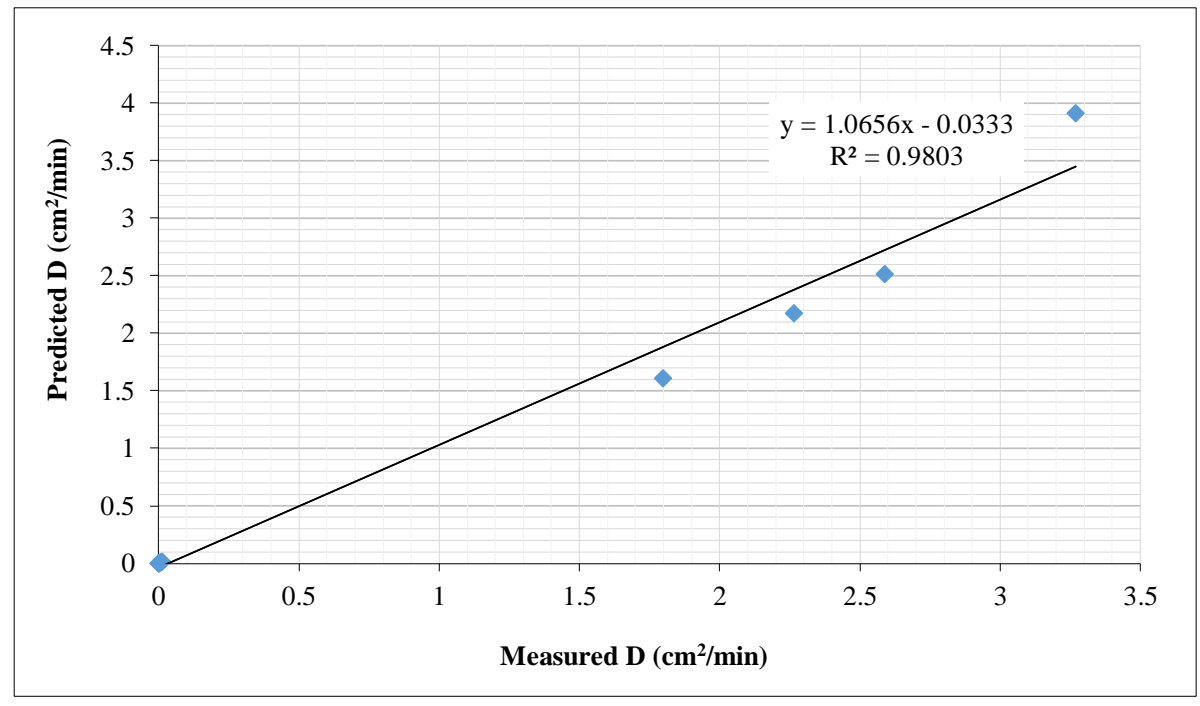

Figure1. Calibration graph showing predicted and measured of dispersion in soil.

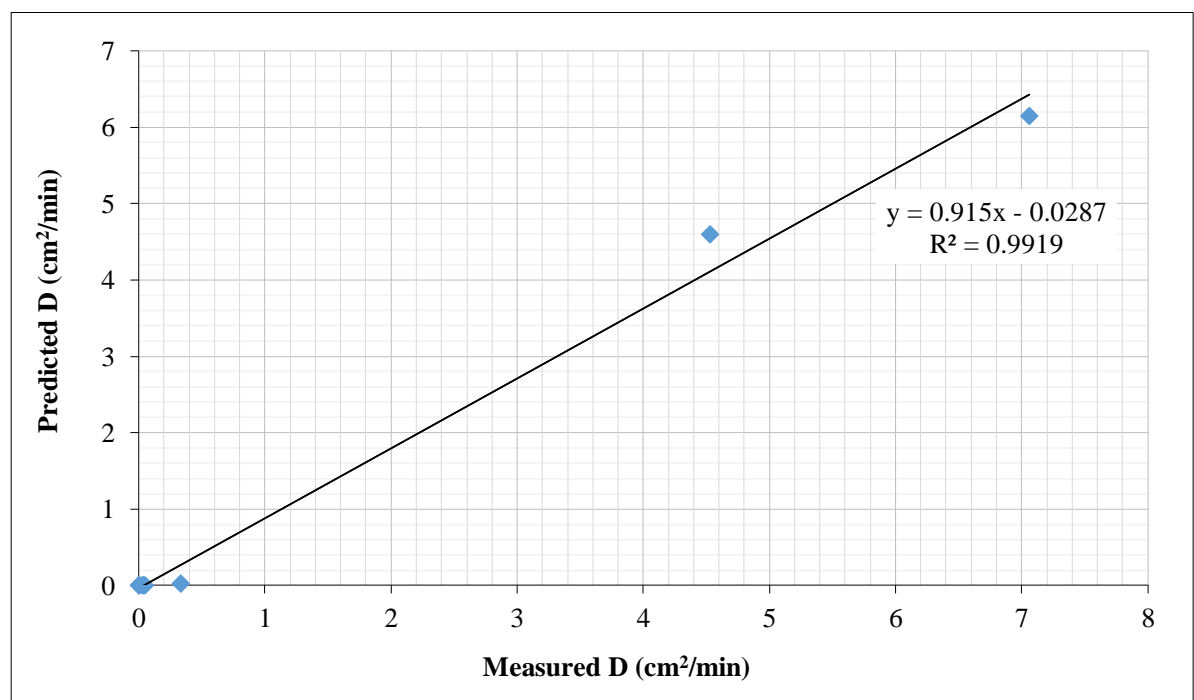

Figure 2. Verification of graph showing predicted and measured of dispersion in soil.

\section{2-8- Comparison of Experimental Data with the Existing Model}

Results obtained from the experiment were fitted into Shao et al., [8] model and regressed. A low value of $r=-0.529$ was obtained against $r=0.943$ obtained in this research. Also, the same data were fitted into De Smeldt and Wierenga [9] model and regressed, in which a low value of $r=-0.524$ was obtained against $r=0.943$ obtained in this research. The predicted curve of Shao et al. [8] and our predicted curve are shown in Figure 3. Looking at the Figure 3, It was observed that the measured values of the dispersion do not agree with values fitted in Shao et al., [8] model. It lacks consistency, since velocity decreased from the first 1.8 to $7.2 \mathrm{~m}$ distance which is good, but sharply increased to $3.96 \mathrm{~cm}^{2} / \mathrm{s}$ at a distance of $9 \mathrm{~m}$. There was an observed decrease from 2.45 to $1.65 \mathrm{~cm}^{2} / \mathrm{s}$ at distances of 10.8 and $14.4 \mathrm{~m}$. There was also a constant decrease to $0.0118 \mathrm{~cm}^{2} / \mathrm{s}$ at a distance of $16.2 \mathrm{~m}$, which further decreased to 0.0079 and $0.0056 \mathrm{~cm} / \mathrm{s} \mathrm{at}$ distances of 18 and $19.5 \mathrm{~m}$ respectively.

Similarly, predicted curve of [9] model in Figure 4 and the predicted curve of this work followed the same trend when plotted against distance from the borehole source. Therefore, we deduced that the model developed in this work is far much better than the two existing models compared, since four parameters were considered unlike Shao et al. [8] and De Smeldt and Wierenga [9] model that evaluated one and two parameters. Also, our regression value $r$ has positive value of 0.945 against Shao, De Smeldt and Wierenga model that has r value as -0.529 and -0.524 respectively. 


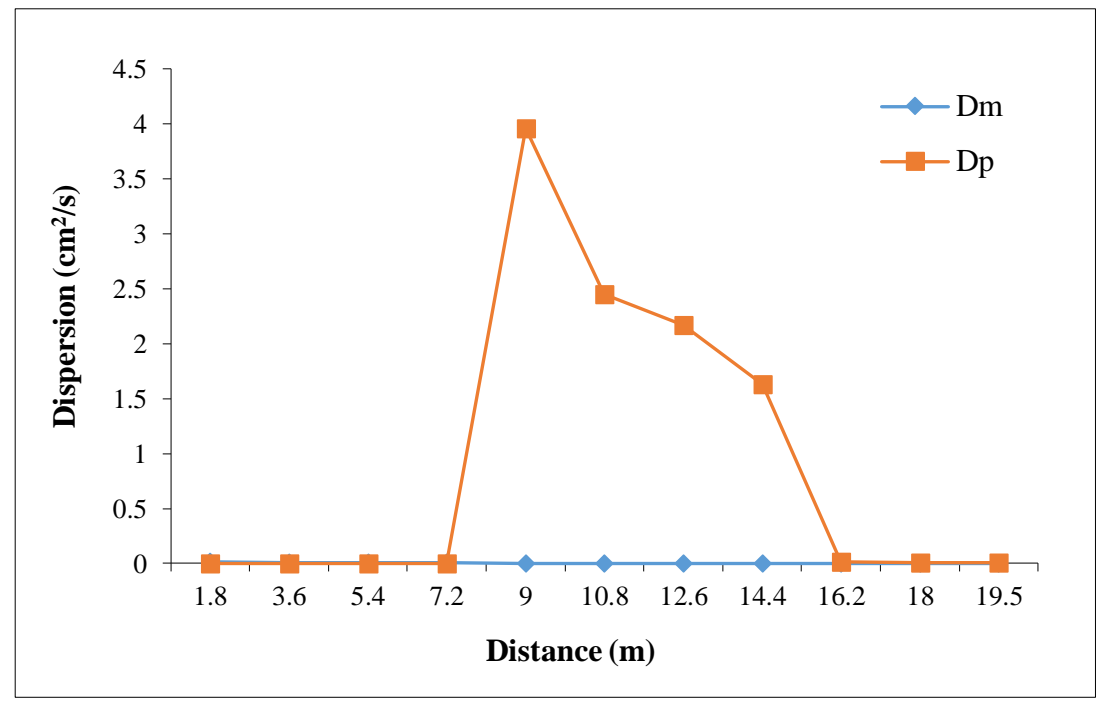

Figure 3. Verification curve for Shao et al. [8] model.

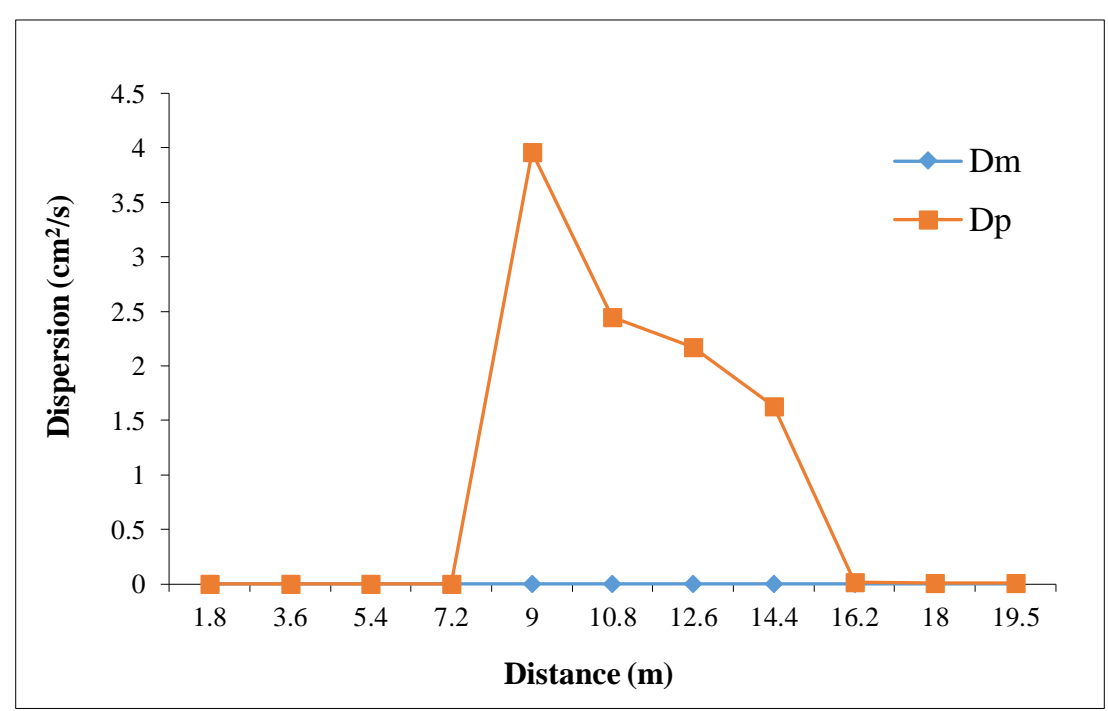

Figure 4. Verification curve for De Smeldt and Wierenga [9] model.

\section{3- Conclusion}

The understanding of solute dispersion in soil is the basis for protection of groundwater from been contaminated. Studies on the dispersion of solute transport through a fabricated column were conducted. The results obtained from the experiment was calibrated and verified. Thereafter, regression model of dispersion, a function of velocity, permeability, average diameter of sieves and time was developed as shown in Equation 1.The derived regression model was used to compare Shao et al. [8] model, De Smeldt and Wierenger [9] model. Data obtained from the experiment were fitted into Shao, et al [8] model and regressed in which a low value of $r=-0.529$ was obtained against $r=0.943$ obtained in the research. Also, the same data were fitted into De Smeldt and Wierenger model [9], and regressed, in which a low value of $r=-0.524$ was obtained against $r=0.943$ obtained in the research. Noteworthy of mention, this regression dispersion model was used in modifying a transport model of a nitrate after being linked to Notodarmojo et al. [10].

\section{4- References}

[1] Haghighi Fashi F, Ejlali F. "A review of uncertainty-based calibration of LEACHM to simulate soil solute transport and water content”. Academia Journal of Scientific Research. 3(10): (October 2015); 146-151. doi: 10.15413/ajsr.2015.0130.

[2] Nimbi IM., Powers S. "Mass transfer correlations for nonaqueous phase liquid dissolution from region with high initial saturation". Water Resour. Res 2003; 39(2): 1030, doi: 10. 1029/2001WR000667.

[3] Bear, J. "Dynamics of fluid in porous media". 1972. American Elsevier. New York

[4] Bear. J. Dynamics of groundwater.1979 McGraw- Hill, New York, New York. 
[5] TINKER, P. B. “A STEADY-STATE METHOD FOR DETERMINING DIFFUSION COEFFICIENTS IN SOIL.” Journal of Soil Science 20, no. 2 (September 1969): 336-345. doi: 10.1111/j.1365-2389.1969.tb01582.x.

[6] Nwaogazie, I.L. "Probability and Statistics for Science and Engineering” Practice. Second edition, 2006 Prints Konzults Lagos.

[7] Agunwamba, J.C. “Engineering Mathematical Analysis. De-Adroit Innovation” .Enugu. Nigeria. 2007; pp 503-511.

[8] Shao A.J.,Wang,S.W. and Chen, X. "Experimental determination of soil hydrodynamic dispersion”. Bulgarian Chemical Contaminations, 2017; pp 113-118.

[9] De Smedt, F., and P. J. Wierenga. "Solute Transport Through Soil With Nonuniform Water Content1." Soil Science Society of America Journal 42, no. 1 (1978): 7. doi:10.2136/sssaj1978.03615995004200010002x.

[10] NOTODARMOJO, S. "Modelling Phosphorus Transport in Soils and Groundwater with Two-Consecutive Reactions." Water Research 25, no. 10 (October 1991): 1205-1216. doi:10.1016/0043-1354(91)90059-y. 